\title{
Further Triterpenes, Steroids and Furocoumarins from Brazilian Medicinal Plants of Dorstenia genus (Moraceae)
}

\author{
Janete H. Y. Vilegas ${ }^{a}$, Fernando M. Lanças ${ }^{a^{*}}$, Wagner Vilegas ${ }^{b}$, \\ and Gilberto L. Pozetti ${ }^{b}$ \\ ${ }^{a}$ Universidade de São Paulo, Instituto de Química de São Carlos, C.P. 780, \\ 13560-970 São Carlos - SP, Brazil \\ ${ }^{b}$ Instituto de Química, Universidade Estadual Paulista, C.P. 355, \\ 14800-900 Araraquara - SP, Brazil
}

Received: November 19, 1996

\begin{abstract}
As frações solúveis em hexano dos rizomas ou das folhas de cinco espécies do gênero Dorstenia (Moraceae) (D. bahiensis K1., D. bryoniifolia Mart ex. Miq., D. carautae C.C.Berg., D. cayapiaa Vell. e D. heringerii Car. \& Val.) foram analisadas por HRGC-MS (cromatografia gasosa de alta resolução acoplada a espectrometria de massas). Foram identificados triterpenos pentacíclicos, esteróides e furocumarinas. HRGC-MS mostrou ser uma ferramenta valiosa para a análise dos terpenóides de Dorstenia spp. Estas substâncias podem estar ligadas à utilização tradicional de Dorstenia spp. como plantas anti-ofídicas.
\end{abstract}

The hexane-soluble fractions from the rhizomes or from the leaves from five Dorstenia (Moraceae) species (D. bahiensis K1., D. bryoniifolia Mart ex. Miq., D. carautae C.C.Berg, D. cayapiaa Vell. and D. heringerii Car. \& Val) were analysed by HRGC-MS (high-resolution gas chromatography - mass spectrometry). Pentacyclic triterpenes, steroids and furocoumarins were identified. HRGC-MS is shown to be a valuable tool for the analysis of terpenoidal compounds from Dostenia species. These compounds may be related to the folk utilization of Dorstenia species as antiophidicals.

Keywords: Dorstenia spp.(Moraceae), high resolution gas chromatography - mass spectrometry, pentacyclic triterpenoids, furocoumarins

\section{Introduction}

The genus Dorstenia L. (Moraceae) includes several Brazilian species which are utilized in folk medicine due to their alleged medicinal properties, mainly in skin diseases and as antiophidics ${ }^{1}$. In these plants, furocoumarins are the most abundant compounds ${ }^{2}$ and these compounds support topical utilization of Dorstenia rhizome preparations in the treatment of skin diseases such as psoriasis and vitiligo ${ }^{3}$.

Despite the strong ethnobothanical indication concerning the antiophidical properties of some Dorstenia species, their pharmacological evaluation is still inconclusive. However, it should be pointed out that the antiophidical utilization of some other Brazilian medicinal plants may be associated to the presence of widespread terpenoids (triterpenoids and phytosterols) with venom-inactivating action $^{4,5}$. The folk indication of triterpenoid-containing plants as "antiophidics" may also be explained by pharmacological action related to the relief of snake bite symptoms, such as analgesic and antiinflamatory effects. These effects may be related to the presence of triterpenoids, as these effects were found even in some triterpene-containing plants with no folk indication as antiophidics ${ }^{6}$.

ln face of the above mentioned data, we have focused the present work on the analysis of further terpenoidal compounds from five Dorstenia species, using HRGC-MS. This technique may be an excellent alternative to the clas- 
sical phytochemical analysis procedures based on preparative-scale chromatographic isolation combined with spectroscopic identification, for the analysis of low-polarity plant extracts. HRGC-MS both avoids time-consuming and relatively expensive purification steps and gives relevant structural information about compounds not easily identified by NMR, IR or UV ${ }^{7}$. However, in the study of medicinal plants, HRGC-MS is still usually restricted to the analysis of low-polarity compounds of low molecular weight (MW 150-250 a.m.u.) such as monoterpenes from essential oils.

\section{Experimental}

\section{Plant Material}

Dorstenia bahiensis KL. (Moraceae) was collected and classified by Dr. T.S. Santos, of Bahia state, Brazil. D. bryoniifolia Mart ex. Miq. was collected at Araraquara, SP, Brazil and classified by Dr. Jose P. Carauta, Jardim Botânico do Rio de Janeiro. D. carautae C.C.Berg was collected and classified by Dr. Gert Hatschbach, at Bocaiuva do Sul, PR, Brazil. D. cayapiaa Vell. was collected and classified by Dr. J.P.Carauta. D. heringerii Car. \& Val was collected by J. Elias de Paula (University Federal of Brasilia, DF, Brazil) at the Reserva Ecológica- IBGE, Brazil.

\section{Extraction of plant material and fractionation of extracts}

General

Plant material was dried at $40{ }^{\circ} \mathrm{C}$, with forced ventilation, during 3 days, before being powdered and sieved. Only material between $0.210-0.350 \mathrm{~mm}$ size was utilized. Plant material (5 g) was macerated with the solvent indicated for each species, at the ratio of 1:10 (w/v), room temperature, during 7 days. When necessary, the extracts obtained were fractionated, as described as follows.

The hexane (Hex) fraction was obtained from the crude extracts: the extract was filtered over active charcoal (Reagen, Rio de Janeiro, Brazil); the solvent was removed under vacuum; the residue was shaken with hexane (Merck), and the hexane-soluble fraction was filtrated, dried over anhydrous $\mathrm{Na}_{2} \mathrm{SO}_{4}$ (Merck) and analyzed by HRGC.

The terpenoidal (Terp) fractions which contained mainly triterpenes and/or steroids were obtained by silica gel open-column preparative liquid chromatography (PLC) of the crude plant extracts and selected by NMR $\left({ }^{1} \mathrm{H}-\right.$ or ${ }^{13} \mathrm{C}$-) analysis of the mixture. Since that the avaiable amount of each hexanic extract obtained as above was very reduced (between 10-100 mg), all the PLC procedure was performed in reduced scale, utilizing glass Pasteur pipettes containing around $500 \mathrm{mg}$ silicagel, and around $5 \mathrm{~mL}$ of each solvent for elution.

\section{Experimental procedure for each species}

D. bahiensis - the leaves were macerated with EtOAc (Merck). The crude extract was cromatographed (PLC, charcoal, eluted with $\mathrm{CH}_{2} \mathrm{Cl}_{2}$ and $\mathrm{EtOH}$, sucessively). The ethanolic fraction was further submitted to PLC (silica gel, 0.063-0.200 mm, Merck, elution with toluene, tolueneEtOAc 1: 1 and EtOAc, sucessively).

D. bryoniifolia - the rhizomes were macerated with hexane. The crude extract was directly analyzed by HRGC.

D. carautae - the whole plant was macerated with EtOAc. The Hex fraction was obtained as described above (General)

D. cayapiaa - the leaves were macerated with $\mathrm{CHCl}_{3}-$ EtOH 1:1 (v/v). The Hex fraction was obtained as described above.

$D$. heringerii - the leaves were macerated with hexane. The crude extract was chromatographed (PLC, silicagel, elution with hexane, hexane-EtOAc 1:1 and EtOAc, sucessively).

\section{Chromatographic analysis}

HRGC-MS analysis were performed by using a HP 5970 MSD, with electron impact ionization $(70 \mathrm{eV})$ coupled to a HP 5890 GC. The column used was a cross-linked 5\% phenyl, 95\% methylsilicone HP-5 (25 m x $0.2 \mathrm{~mm}$ x $0.33 \mu \mathrm{m}$ ), furnished by Hewlett-Packard, U.S.A.. Samples were injected using the split mode (split ratio 1:30), with injector temperature and GC-MS interface temperature both at $280^{\circ} \mathrm{C}$. Column temperature was programmed from $150{ }^{\circ} \mathrm{C}(2 \mathrm{~min})$, at $8{ }^{\circ} \mathrm{C} / \mathrm{min}$ to $290^{\circ} \mathrm{C}$ (held during $20 \mathrm{~min}$ ). Hydrogen was used as carrier gas. MS scan range was 50 to 500 a.m.u.. Data were processed on a HP 7946/HP 9000-300 CPU.

HRGC-FID analysis were performed on a HP 5890 GC, using the same column with the same temperature programming utilized for HRGC-MS analysis. Detector temperature was $290{ }^{\circ} \mathrm{C}$, and data were obtained on a HP 3396A integrator. Hydrogen was utilized as carrier gas, at the average linear velocity of $40 \mathrm{~cm} / \mathrm{s}$.

\section{Analysis of fatty acids}

Fatty acids were identified by HRGC-MS as their methyl esters, after esterification with diazomethane of the fractions containing these compounds.

\section{ldentification of the chemical constituents}

Identifications were made by comparison of retention times, obtained at identical chromatographic conditions of the analyzed samples and authentic standards or by co-injection. In both cases, chromatographic data were considered together with the comparison of MS data with those from authentic standards, obtained at similar ionization conditions (EI, $70 \mathrm{eV}$ ) in our laboratory. Tentative identi- 
fications were made by analysis of the fragmentation data, comparison with literature MS data ${ }^{8,9,10}$ and computer search in the NBS library.

\section{Results and Discussion}

HRGC-MS was applied both to the analysis of crude extracts and of fractions obtained from PLC. For the analysis of crude extracts, due to the presence of more polar compounds, only the hexane-soluble compounds were analyzed, since this solvent can selectively extract compounds appropriate to GC analysis, including low-functionalized steroids and triterpenoids. Despite a relatively longer analysis time, preliminary work with standards showed that derivatization of the triterpene and steroid alcohols is not essential, with the advantage of allowing direct comparison with literature data of underivatized compounds ${ }^{9}$.<smiles>[R]c1c2ccoc2c([R])c2oc(=O)ccc12</smiles>

$\begin{array}{llll} & \mathbf{R}_{\mathbf{1}} & \mathbf{R}_{\mathbf{2}} & \\ \mathbf{1 a} & \mathrm{H} & \mathrm{H} & \text { psoralen } \\ \text { 1b } & \mathrm{OMe} & \mathrm{OMe} & \text { bergapten } \\ \text { 1c } & \mathrm{OMe} & \mathrm{OMe} & \text { isopimpinelin } \\ \text { 1d } & \mathrm{OC}_{10} \mathrm{H}_{15} \mathrm{O}_{2} & \mathrm{OMe} & \end{array}$<smiles>[R]c1c(OC)c2ccc(=O)oc2c2ccoc12</smiles>

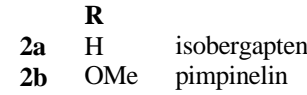<smiles>[R]C1C2CCC3(C)C([R])C4C(=CCC5C4(C)CCC4C(C)(C)C([R])CCC45C)C3(C)CCC2(C)CCC1([R])C</smiles>

$\begin{array}{lllll} & \mathbf{R}_{\mathbf{1}} & \mathbf{R}_{\mathbf{2}} & \mathbf{R}_{\mathbf{3}} & \\ \text { 3a } & \mathrm{H} & \mathrm{Me} & \mathrm{H}, \mathrm{OH} & \alpha \text {-amyrin } \\ \text { 3b } & \mathrm{Me} & \mathrm{H} & \mathrm{H}, \mathrm{OH} & \beta \text {-amyrin } \\ \text { 3c } & \mathrm{H} & \mathrm{Me} & \mathrm{H}, \mathrm{OAc} & \alpha \text {-amyrin acetate } \\ \text { 3d } & \mathrm{Me} & \mathrm{H} & \mathrm{H}, \mathrm{OAc} & \beta \text { amyrin acetate } \\ \text { 3e } & \mathrm{H} & \mathrm{Me} & \mathrm{O}= & \alpha \text {-amyrone } \\ \text { 3f } & \mathrm{Me} & \mathrm{H} & \mathrm{O}= & \beta \text {-amirone }\end{array}$<smiles>CC(=O)OC1CCC2C(=CCC3C2(C)CCC2(C)C4CC(C)(C)CCC4(C)CCC32C)C1(C)C</smiles>

4 glutinol acetate<smiles>C=C(C)C1CCC2(C)CCC3(C)C(=CCC4C5(C)CCC(OC(C)=O)C(C)(C)C5CCC43C)C12</smiles><smiles>CC(=O)OC1CCC2(C)C3CCC4(C)C(=CCC5(C)CCC(C)(C)CC54)C3(C)CCC2C1(C)C</smiles>

5 taraxerol acetate

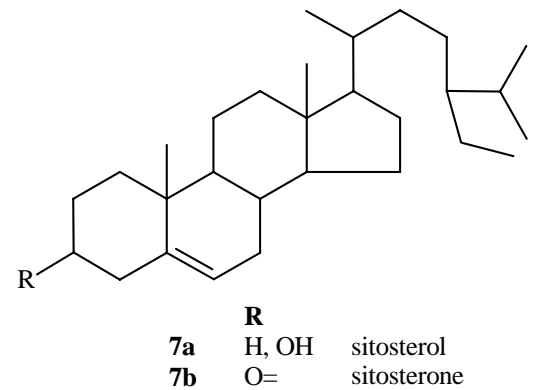

Figure 1. Chemical structure of the compounds detected by HRGC-MS in Dorstenia samples. 
The HRGC-MS -TIC profile of the Dorstenia crude extracts showed some similarity between the chemical pattern of leaves and rhizomes, even from different species: the furocoumarins are eluted first, followed by the steroids, while the triterpenes are eluted later. FID integration of the peaks indicated a predominance of the furocoumarins over the aliphatic compounds.

HRGC-MS-TIC allowed identifying several compounds from Dorstenia samples (Table 1 and Fig. 1). The chemical composition of all Dorstenia samples herein examined showed to be very similar (Table 1), and some of the identified compounds have already been reported from other Dorstenia species ${ }^{2}$. All the triterpenes were found in small amounts (yield from vegetal material: $0,1 \%$ or less).

The procedure herein adopted limited the scope of the compounds analyzed to the less polar constituents. More highly funtionalized or polar molecules such as syriogenin, which was previously found in $D$. contrajerva $a^{11}$ might not be detected, due to the selective extraction of low-polarity compounds and also due to the lower volatility of the polar compounds; the knowledge of this limitation is important for the final option for HRGC-MS analysis. Therefore, we are studying the more polar compounds from Dorstenia hydroalcoholic extracts by using conventional procedures.

\section{Identification of the compounds}

The prenylated derivative of bergapten, 1d, was found only in D. bahiensis. Its identity was confirmed by comparison of retention time and MS data with those of an authentic sample isolated from D. cayapiaa $^{12}$.

Using only MS data, it was not possible to identify the furocoumarins 1a-c and $\mathbf{2 a - b}$, due to the similarity of the fragmentation patterns of the linear and angular isomers. Their identification also required comparison with $t_{R}$ data of authentic samples of some furocoumarins using the same chromatographic conditions as in this work.

Most of the triterpenes found belong to the oleanane/ursane series, characterized by a base peak at $\mathrm{m} / \mathrm{z}=218^{9}$. Unequivocal differentiation between $\alpha$ and $\beta$-amyrin re- quired co-injection with authentic samples, since these triterpenes have very similar MS spectra (in the chromatographic conditions utilized, $\beta$-amyrin elutes first). In the operational conditions of the MSD system utilized in this work, $\alpha$ - and $\beta$-amyrin could be differentiated by examination of the relative intensities of the peaks at $\mathrm{m} / \mathrm{z} 189$ and 203: $\beta$-amyrin has a $\mathrm{m} / \mathrm{z} 203$ peak around twice the intensity of the $\mathrm{m} / \mathrm{z} 189$ peak, while $\alpha$-amyrin spectra shows both peaks with similar intensity.

ln the hexane extract of $D$. bryoniifolia, two triterpenes were found with base peaks at $\mathrm{m} / \mathrm{z} 218$, but both with a peak at $\mathrm{m} / \mathrm{z} 424$, supposed to be the molecular peak, instead of $\mathrm{m} / \mathrm{z}=426$ as in the case of $\alpha$ - and $\beta$-amyrin. Exchange of an hydroxy group for a keto group leads to a decrease of molecular weight and polarity, which leads to a lower $t_{R}$ in the column utilized for the HRGC analysis of these compounds. Besides, MS spectra of these compounds shows a peak at $\mathrm{m} / \mathrm{z} 205$, due to the fragmentation of a 3-keto-system involving rings $\mathrm{A}$ to $\mathrm{C}$, and at $\mathrm{m} / \mathrm{z}=203$, corresponding to the fragment originating from methyl loss of the diene portion originated from retro Diels-Alder fragmentation of a $\Delta^{12}$-unsaturated oleanane or ursane ${ }^{9}$. With these data, they were tentatively identified as being $\alpha$ - or $\beta$-amyrone (3e-f). Final identification was made by using $\alpha$ - and $\beta$-amyrin fragmentation as models: in the keto compounds, a difference was also observed in the relative intensity of the peaks at $\mathrm{m} / \mathrm{z}=189$ and 203, which originate from further fragmentation of the $\mathrm{m} / \mathrm{z}=218$ ion, the latter indicating the C-ring opening of a D,C-unsubstituted $\Delta^{12}$-oleanene or ursene $^{9}$. In an analogous way to $\alpha$ - and $\beta$-amyrin, we have assigned the compound with the more intense $\mathrm{m} / \mathrm{z}=203$ peak as being $\beta$-amyrone (3f) and the $\alpha$-amyrone structure (3e) was assigned to the compound with $\mathrm{m} / \mathrm{z}=189$ and 203 peaks with similar intensity. Chromatographic data also supports these assignments, since the peak corresponding to $\mathbf{3 e}$ in the TIC has a lower $t_{R}$ than $\mathbf{3 f}$ in the same elution sequence as for the $3-\mathrm{OH}$ terpenes.

Table 1. Compounds identified by HRGC-MS in Dorstenia samples (crude extracts or terpenoidal fractions).

\begin{tabular}{|c|c|c|c|c|}
\hline \multirow[t]{2}{*}{ Species } & \multicolumn{4}{|c|}{ Compounds } \\
\hline & furocoumarins & triterpenes & steroids & others \\
\hline D. bahiensis & $\mathrm{tBg}$ & $\alpha$-Am, $\beta$-Am, $\alpha$-Ac, $\beta$-Ac, GlAc & Stn & \\
\hline D. bryoniifolia & $\mathrm{Bg}, \mathrm{iBg}, \mathrm{Pi}, \mathrm{Pi}$ & $\alpha-A m, \beta-A m$ & & \\
\hline D. carautae & & $\alpha-A m, \beta-A m$ & & \\
\hline D. cayapiaa & & $\alpha-A m, \beta-A m, \alpha-A c, \beta-A c$, TxAc, $\beta$-Ar & Sit & $\mathrm{FA}\left(\mathrm{C}_{16}\right.$ and $\left.\mathrm{C}_{18}\right)$ \\
\hline D. heringerii & & $\alpha-A c, \beta-A c$, LpAc, GlAc & $\mathrm{a}$ & $\alpha$-tocopherol \\
\hline
\end{tabular}

a tentative identification

$\mathrm{Bg}$ : bergapten; iBg: isobergapten; Pi: pimpinelin; iPi: isopimpinelin; $\alpha$-Am: $\alpha$-amyrin; $\beta$-Am: $\beta$-amyrin; $\alpha$-Ac: $\alpha$-amyrin acetate; $\beta$-Ac: $\beta$-amyrin acetate; $\beta$-Ar:, $\beta$-amyrone; GlAc: glutinol acetate; TxAc: taraxerol acetate; LpAc: lupeol acetate; Stn: sitosterone; Sit: sitosterol; FA: fatty acids. 
Glutinol acetate was identified by analysis of its fragmentation data and comparison with an authentic sample of simiarenol, isolated from Dorstenia asaroides ${ }^{13}$. Despite the lupane-type ring $\mathrm{E}$ of the latter, which leads to some characteristic peaks related to the isopropyl group, both glutinol and simiarenol have great similarities in their MS spectra due to the similar structure of rings $\mathrm{A}$ to $\mathrm{D}^{14}$, the most important feature being the base peak at $\mathrm{m} / \mathrm{z} 274$, followed by a (274-Me) peak at $\mathrm{m} / \mathrm{z} 259$, which characterizes $\Delta^{5}$-unsaturated skeleta ${ }^{10}$.

Taraxerol acetate was identified only by MS, mainly due to the base peak at $\mathrm{m} / \mathrm{z} 204$, which originates from rings $D$ and $E$ of an $\Delta^{14}$-taraxerene. Another important peak is $\mathrm{m} / \mathrm{z} 344$, which originates from a retro Diels-Alder decomposition with ring-D opening and confirms both the unsaturation and the presence of an acetoxy group at C- $3^{9}$.

The other triterpenes which are not discussed herein were identified by co-injection with authentic samples; other compounds were identified by direct comparison of MS and $t_{R}$ data with authentic standards (sitosterol, sitosterone, $\alpha$-tocopherol) or by chromatographic data, confirmed by interpretation of MS fragmentation (fatty acids, analyzed as their methyl esters). Some significant MS data of the identified compounds from Dorstenia are listed in Table 2.

A compound detected in $D$. heringerii, that was identified tentatively as a steroid, requires further MS studies, possibly by using soft ionization techniques (not available

Table 2. Relevant MS data of the compounds identified from Dorstenia samples (EI, $70 \mathrm{eV}$ ).

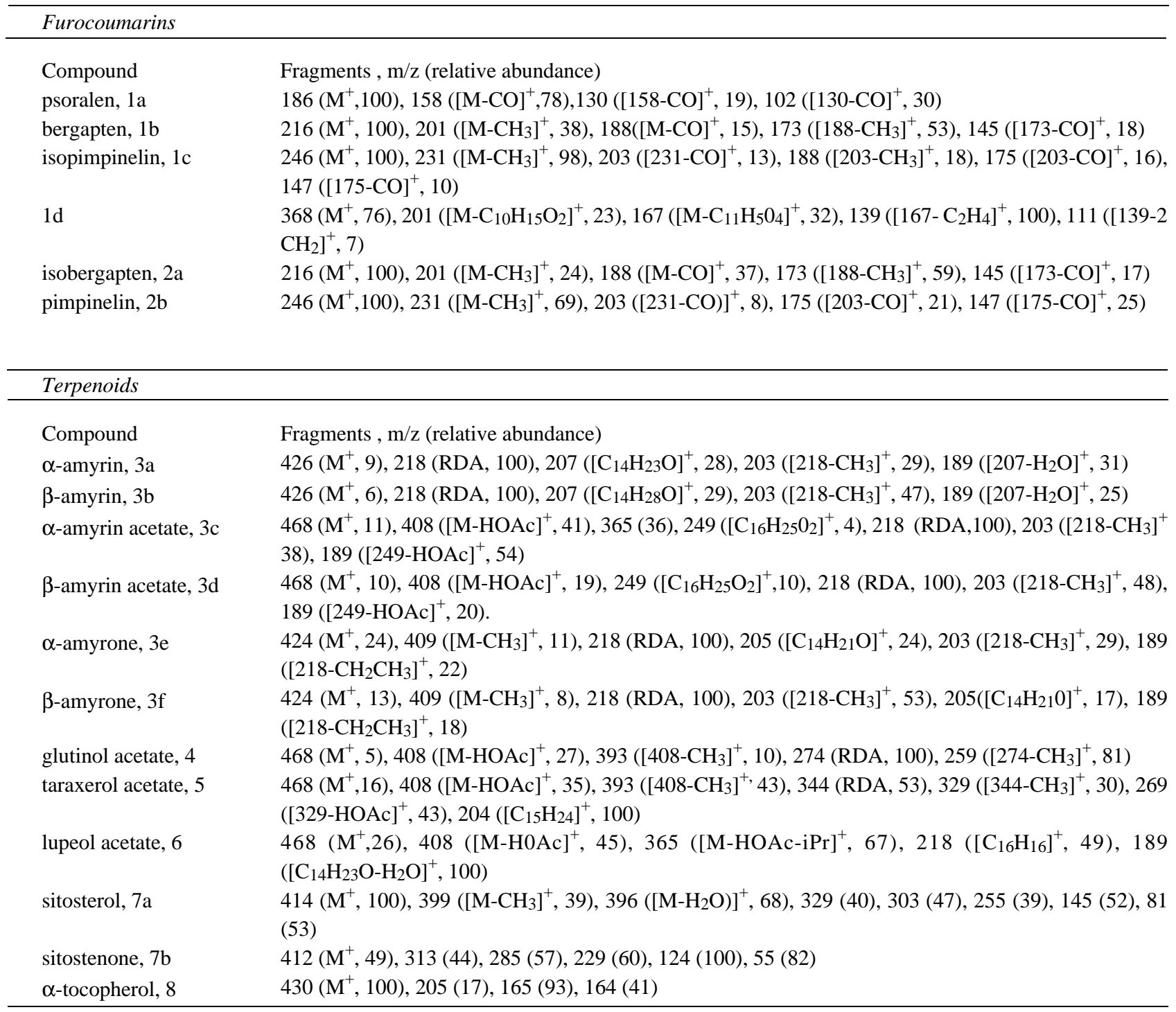

RDA: retro Diels-Alder. 
in our laboratory during the present work), since this compound is present at a very low level, which prevents its isolation through usual phytochemical procedures.

Figure 2 shows a typical chromatographic profile from dechlorophyllated crude Dorstenia extracts. The extracts obtained from the leaves require a clean-up procedure for removal of the chlorophylls (filtration over active charcoal, described in Experimental), while the crude extracts obtained from the rhizomes could be directly analyzed by HRGC-MS. In a previous work we have shown that SFE$\mathrm{CO}_{2}$ (supercritical fluid extraction using $\mathrm{CO}_{2}$ ) also furnishes rhizome extracts suitable for direct analysis ${ }^{15}$.

The TIC-MS data obtained from the Hex-fraction and from the Terp-fractions were almost the same for the terpenoidal compounds (Fig. 3), and the identification of most of the triterpenes and steroids was possible even in Hex-fraction. As the Terp-fractions required more isolation steps (with greater consumption of solvents and silica gel adsorvent) than the Hex-fractions, the HRGC-MS analysis of a crude dechlorophyllated hexane extract from Dorstenia samples is sufficient to obtain relevant information concerning their chemical composition. The utilization of small amounts of plant material is very important in the case of Dorstenia genus, since the analysis of the rhizomes (the most valuable part of these plants, according to folk

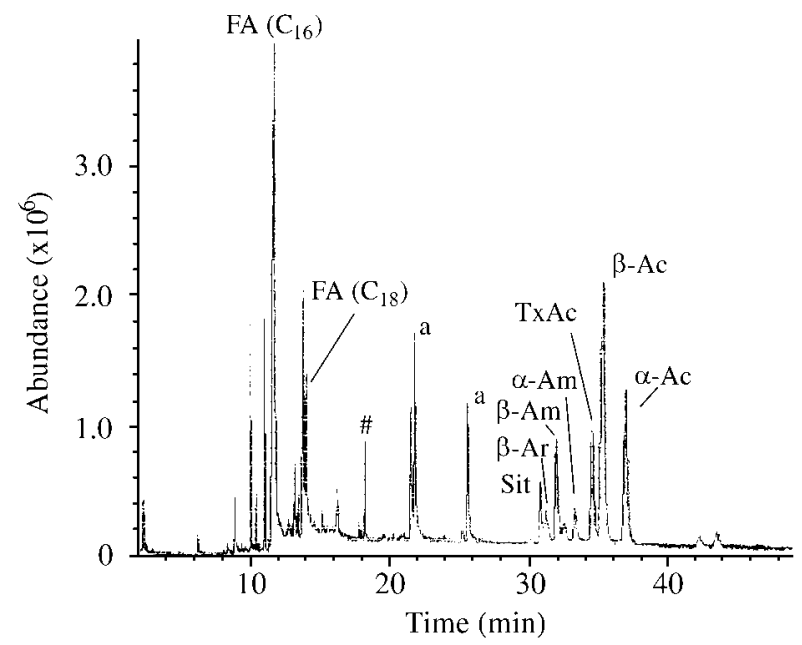

Figure 2. HRGC-MS-TIC chromatogram of a typical crude Hex-fraction from Dorstenia cayapiaa rhizomes (\#: ftalate; for identification of the other peaks see symbols in Table 1).

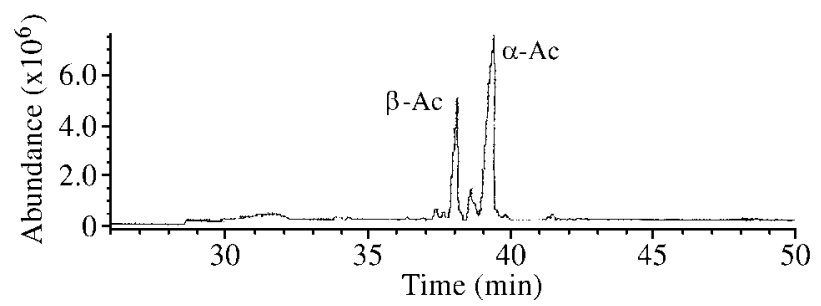

Figure 3. HRGC-MS-TIC chromatogram of a typical Terp-fraction from Dorstenia heringerii leaves. medicine indications) leads to the destruction of the plant, and the native Dorstenia population is diminishing in Brazil.

\section{Conclusions}

Bergapten, as well as the triterpenes $\beta$-amyrin and sitosterol, have already been associated with the snakevenom inactivating action of some Brazilian medicinal plants ${ }^{5}$. Thus, the utilization of Dorstenia plants as antiophidicals may be inferred to be both due to a venom-inactivating action and to analgesic and antiinflamatory properties of the several triterpenes. These results also pose the question if biologically-guided fractionation is an appropriate procedure in the search for the active compounds of medicinal plants such as those of Dorstenia genus, since these active molecules may be minor compounds, with small and/or non-specific pharmacological actions when studied as isolated compounds.

HRGC-MS has proved to be a very powerful tool affording both the separation and the individual characterization of isomers which could not to be separated by conventional PLC procedures. Further to the preliminar report of some of the data herein presented ${ }^{16}$, a paper concerning the analysis of triterpenes from Brazilian Polypodiaceae was published, but with the aid of preparative purification steps and chemical transformations, for obtention of reference samples of some triterpenes not found commercially ${ }^{17}$.

In the screening of medicinal plants from the same genus, which often requires the analysis of many species with similar chemical composition (as in the case of Dorstenia genus), and specially in the particular case of the pentacyclic triterpenes, MS data furnish a fast differentiation among important skeleta, some of them with potential biological interest.

\section{Acknowledgments}

To CNPq, FAPESP and FUNDUNESP, for fellowships and research grants, and to the Centro de Pesquisas de Paulinia (Rhodia S.A.) for furnishing some standards used in this work.

\section{References}

1. Corrêa, M. Pio In Dicionário das plantas úteis do Brasil e das exóticas cultivadas; Ministério da Agricultura, Rio de Janeiro, 1926, vol. 2., p. 161.

2. Vilegas, W.; Vilegas, J.H.Y.; Pozetti, G.L.Rev. Cienc. Farm. 1992, 14, 133.

3. Martins, J.E.C.; Pozetti, G.L.; Sodré, M. Int. J. Dermatol. 1974, 13, 124.

4. Mors, W.B.; Nascimento, M.C. do; Parente, J.P.; Silva, M.H. da; Melo, P.A.; Suarez-Kurtz, G. Toxicon 1989, 27, 1003. 
5. Pereira, N.A.; Pereira, B.M.R.; Nascimento, M.C. do; Parente, J.P.; Mors, W. Planta Med. 1994, 60, 99.

6. Freire, S.M.de; Ada, J.; Emin, S.; Lapa, A.J.; Souccar, C.; Torres, L.M.B. Phytother. Res. 1993, 7, 408.

7. Vilegas, J.H.Y.; Lanças, F.M. J. High Resol. Chromatogr. 1995, 18, 129.

8. Budzikiewicz, H.; Djerassi, C.; Williams, D.H. In Structure elucidation of natural produtcs by mass spectrometry; Holden-Day, San Francisco, 1964 vol. 2.

9. Budzikiewicz, H.; Wilson, J.M.; Djerassi, C. J. Am. Chem. Soc. 1963, 85, 3688.

10. Ogunkoya, L. Phytochemistry 1981, 20, 121.

11. Casagrande, C.; Ronchetti, F.; Russo, G. Tetrahedron 1974, 30, 3587.
12.Llabrès, G.; Baiwir, M.; Vilegas, W.; Pozetti, G.L.; Vilegas, J.H.Y. Spectrochim. Acta 1992, 48A, 1347.

13. Vilegas, W.; Vasoncelos, E. de C.; Pozetti, G.L.; Vilegas, J.H.Y. Rev. Ciênc. Farm. 1997, 18, 000.

14. Aplin, R.T.; Arthur, H.R.; Hui, W.H. J. Chem. Soc., Series C 1966, 1251.

15. Vilegas, J.H.Y.; Lanças, F.M.; Vilegas, W.; Pozetti, G.L. Phytochem. Anal. 1993, 4, 230.

16. Vilegas, J.H.Y.; Lanças, F.M.; Vilegas, W.; Pozetti, G.L. In Proceedings of the 16th International Symposium on Capillary Chromatography; Sandra, P.; Devos, G. Eds., Hüthig, Heidelberg, 1994, vol. 1., p. 935.

17. Patitucci, M.L.; Pinto, A.C.; Cardoso, J.N. Phytochem. Anal. 1995, 6, 38.

FAPESP helped in meeting the publication costs of this article 